\title{
Study on the interacted influence of aesthetic conception of folk and scholar classes on art of the Song dynasty
}

\author{
Chenyang $\mathrm{Li}^{1, \text { a }}$ \\ ${ }^{1}$ Department of literature and arts, Jinshan college of Fujian Agriculture and Forestry University, \\ Fuzhou, Fujian ,China \\ aqufeng.yang@163.com
}

Keywords:porcelain decoration, seal art,aesthetic interaction

\begin{abstract}
The artistic expression of the porcelain ornamentation and seal art in the Song Dynasty reflects the interaction between the folk and the scholar's aesthetic consciousness, which is the important symbol of social mobility. By contrasting the differences between the Tang Dynasty and the Song Dynasty porcelain ornamentation and seal art, this paper explains the origin of the artistic style of the porcelain in the Song Dynasty from the angle of the aesthetic interaction between the folk and the scholar stratum, which is elegant, simple, positive and fresh styles.
\end{abstract}

\section{Introduction}

Various art categories gradually mature on the Song dynasty, showing a unique artistic style. Scholar class aesthetic in the social aesthetic ideology to obtain the mainstream position, from Chinese painting, seal to porcelain, scholar aesthetic effect is obvious. Porcelain of the Song dynasty in the history of China is brilliant, that both in the types, styles, or burning process and other aspects, have reached an unprecedented height. The theme, universal content, decorative forms and a number of wonderful natural decorations presented by the Patterns on porcelain of Song dynasty all have reflected the folk and scholar classes' aesthetic culture, which have strong implication of folk interest.

China's seal art also have had vast influence and had thousands of years, and is the combination of practical and artistic. In the course of the development of the literati painting, the seal has gone through the imperial treasures of the Tang Dynasty, and the winds of the various departments have been developed. The development of the stamps of the Song and Yuan Dynasties has been developed. The famous seal artist has appeared in the Song dynasty and it is said that the literal class have rise in this period.

\section{Interaction of aesthetic consciousness of scholar and folk classes of Song dynasty}

The political atmosphere of Song dynasty was relaxed. Shifted from relatively fixed bigwigs system of Tang dynasty to scholar ruling that make the marked change of socio-political structure. Scholar class communicates civil society with upper level. Like the famous poet said a man morning is a governor who can work with the Emperor and yesterday night is a farmer. Social mobility by widening the circulation enhancement between different classes to society brought a new sense of aesthetic and artistic style.

The interactive of aesthetic conception between folk and upper class in the Song dynasty have generated diverse aesthetic styles, reflecting the changes in the social system. Scholar class comes from folk class, and has ultimate-dependent of simplicity, naturalness and elegant aesthetics reflected of folk culture, which can draw through many of the poems that praise natural live of daily life. Meanwhile, scholar class as a relatively independent group, receives the spirit of Taoism and Confucianism that have the beyond aesthetic consciousness, which could have deduced by landscapes pictures.

Sha Menghai,the famous seal artist believes that because of the literati painting rise in the Song dynasty ,which poetry, books, paintings writers that they have used the painting on the seal, both show solemn and complex beauty. Mi Fu, the famous artist in the Song dynasty, is the first seal maker 
make their own seal, printed their own scholar. Can also be said that the strict sense of the famous seal carvings, at least to the Song Dynasty began to appear, which is much worse than the poet.

\section{The aesthetic style of porcelain and seal art in Song dynasty}

Porcelain decoration and color are related closely with aesthetic consciousness of nobility class in the Tang dynasty. Celadon, white porcelain are the representation of Tang dynasty, that use of a single form of Lotus and Peony. Jade is symbols of the traditional upper class of society, and the celadon, the white porcelain in the Tang dynasty all use jade color that in accordance with social aesthetic declination. Lotus and peony in the Tang dynasty represent social status and social nobility; meanwhile, Lotus flower is the symbol of Buddhism, which is the most respected religious of upper class during the Tang dynasty. The Peony is regarded as the national flower of in the Tang dynasty, which has more political power in the period of Empress Wu Zetian because of the mystery legend about herself.

To some extent Song pottery techniques and artistic style inherited from the Tang dynasty, but had significant changes about color and ornament. The five famous kilns of the Song dynasty were $\mathrm{Ru}$ kiln, Jun kiln, Guan kiln, Ge kiln and Ding kiln, which were representative of advanced method, exquisite and ingenious skills about china of the Song dynasty [1]. Ru kiln located in Ru Zhou city of Henan province, which was famous for Celadon. The china produced by Ru kiln had attractively sticky and gleaming ceramic glaze that like sky-blue, which had minute clay soil and had slivers in the surface of porcelain.

In the famous book Tan Zhai Bi Heng wrote by Ye Zhi said that the most famous porcelain in the Song dynasty is Ru kilns which more popular than Ding kiln. Glaze mainly azure, sky blue, pale pink, pink, white, etc, glaze thin and shiny, glaze bubble large and sparse. The porcelain of Ru kiln glazed with small patches, known as crab claw pattern, which early most of the ornaments were plain and no grain, mainly in glaze to win, late print engraving, hidden under the glaze.

Ding kiln began to burn in the Tang Dynasty, in the Northern Song Dynasty to reach the heyday. The white porcelain of Ding kiln with printing flowers was treasures. The porcelain of Ding kiln with tires firm, and more to printing, carved, designated as a decorative flower, peony, lotus, chrysanthemum, pomegranate, dragon pattern, fish water lines, etc, and characterized lines lively and smooth, precise and precise printing.

Jing Dezhen kiln white green porcelain, which like jade with pure crystal, is regarded as shadow green. Guan kiln in the Northern Song Dynasty in Kaifeng was famous with purple iron foot. Long Quan kiln was known as fresh, elegant and beautiful style [2].

In addition, Hebei Cixian Cizhou kiln was affluent with folk-art, and mainly burn white pottery with black ornament. Jiangxi Jizhou kiln is the famous kiln in the south of the Yangtze River, firing black porcelain, white porcelain, carved and painted black and white porcelain, creating a leaf and paper cutting and paste, under glaze decorative wood leaf texture and engraving patterns, with natural simplicity style [3].

Looking at the several of Song porcelain kilns, its decorative patterns on the whole have the following characteristics. First of all, flower patterns were symbol of auspicious peonies, like lotus, chrysanthemum, pomegranate, etc. Printed patterns were fine, ingenious skills. Secondly, in the outside of pattern that ornamented by smooth smelting lines have manifested with gentle and exquisite styles, which were so popular in that period. Thirdly, the pattern of engraved ornaments had shown different shades of the slope, so that patterns have different shades of change. Patterns mostly were peony, Lotus and so on.

In the Song dynasty, seal have used by literal class to emphasize individual aesthetic. In the long process of united of seal and painting, that the seal in the picture is no longer restricted to the supplement of signature, which is the indispensable constituent of painting. The literal class uses the seal to supplement the drawings, to balance the configuration and so on. The various seal used by literals that have different styles and different calligraphy which can be seen as a window which concentrates on long historic signification of culture. 


\section{The reflection of aesthetic interaction on porcelain patterns and seal art of the Song dynasty}

The aesthetic conception of scholar class of Song dynasty was influenced by the Confucian significant, especially Neo-Confucianism. Neo-Confucianism insisted that excessive indulgence of human desire had led to the chaos and the collapse of the Tang Dynasty. Neo-Confucianism holds that destroy of human desire was the inborn principle of the world. The empire of Song Zhenzong has issued an edict which said that since nearly the aesthetic declination is more than fuddy-duddy and extravagant. From now will be punished if a literal man uses floating words. Because of the advocate of simplicity and natural styles, the pattern of ornament and seal was classical and pure at Song dynasty.

The scholar stratum of the Song Dynasty was favored in the social system, the distribution channels of different classes were relatively smooth, and the style of the porcelain was freely, and Seal turn to highlight the individual aesthetic style.In the Tang Dynasty, the single-shaped lotus and peony were replaced by a variety of folk aesthetic art, such as peony, lotus shape more free and easy, increased pomegranate ornamentation, and folk aesthetic.

In the folk aesthetic, the fish play with lotus is a folk language, referring to men and women in love. In the wedding, the common large-scale paper-cut works, occupy a prominent position is often fish play with lotus. The screen cut out delicate Lotus, a happy fish, shuttling among the lotus. Here, the lotus symbolizes the gentle female, the fish symbolizes the male. Lotus Chinese pronunciation Lian implicates the continuous, it is to say a couple can bring several boys, and express the hope of married life together with the happy life.

Peony in the concept of folk life is wealth. Large-scale elegant pattern was the sign of people's strong desire for a better life. The future of life is mysterious, and seems destined not to be flat. Especially in ancient times, the level of productivity is very low, people often under the natural threat. To face of natural disasters, people only hope that a year better than other year. Of course, also want to spend one day rich. Therefore, the peony has become everyone's favorite content. Almost in all categories of folk art, there are a lot of peony performances. Such as wood carvings in the houses, with peony carved inlaid in the windows, eaves or shadow wall, the metaphor of family wealth, and in the folk paintings, the use of peony design for decoration, a symbol of the age of abundance.

Pomegranate patterns are also well-known genre. In the folk mystical interpenetration of thinking, some of the functions of foreign objects through artificial means have an impact on specific groups of people. People in the observation found that pomegranate have a lot of seeds, it is also the equivalent of the son. But human fertility far less than pomegranate, Thus people want to turn the power of pomegranate to the people. Through re-processing methods, the pomegranate paper cut out to paste the new home. In the public view, through this method, people may be as much as the pomegranate to give birth to his offspring.

A porcelain attached to the top of the lotus in accordance with the shape of the pot body clever tactfully, lotus petals blossom followed in order to start, elegant and orderly. White porcelain produced by $\mathrm{Ci}$ Zhou kiln with white fine boutique, wrapped like flowers have been carefully hollow, and then paste in the porcelain surface [4]. The branch twigs beautiful, elegant, like the wind had been blowing, slightly swaying, the leaves slightly inclined to the wind that the flowers are like can not afford, like to fall, there is a toughness to make it present out of the maximum tension state. Careful observation and found that this is a peony, flowers have been in full bloom, in the middle there is still a huge heart-shaped bud. This flower has not been opened, which a symbol of happiness is after had the child. So, that is to say, this peony is a symbol of the people looking forward to the rich and the wishful life and the simple desire of more children.

As for the seal art, which from the practical purpose to emphasis on individual aesthetic freedom, this aesthetic concept based on the literati can freely express the subjective emotional premise. Seal from the folk class for credit to the scholar class for emotion, which is the performance of the spirit of the literati. The rise of literati conception makes the literati painter which use seal more clever and the use of the process more ingenious. So the combination embodies the harmony of practical and aesthetic of seal art. Literati painstaking because they are blessed in many aspects of cultivation which can be a good use of calligraphy theory and painting theory into the use of seal art. 


\section{Conclusion}

The Song porcelain decoration influenced by the upper and lower layers of social interaction and interaction, showing free, pure and lively aesthetic style, to achieve the organic unity of art and thought. The simple aspirations of scholar class and the folk people is the foundation of our national culture, and promote the era of folk art heritage and development. When it appears in the Song porcelain, it makes it look changed, so that it presents a whole elegant, simple and fresh style, exudes a permanent artistic charm.

Chinese literati are deeply influenced by traditional culture, and they have always attached great importance to the cultivation of many aspects. Their paintings pay more attention to knowledge and talent. They pay attention to the spirit of writing and painting. They are the temperament and wild style of the seal art.

\section{Acknowledgement}

Supported by Fujian Province Department of Education, research of Fujian Seal cutting art development process, Grant No:JAS150832.

\section{References}

[1] Central Academy of art history Department of art series, a brief history of Chinese art, higher education press, pp.97-163,1990.

[2] Tian Zibing: The history of Chinese arts and crafts, Shanghai knowledge Publishing House, pp.223-257,1994.

[3] Xia Yanjing: Art history of the process, Liaoning fine arts publishing House, pp. 156 -159,2001.

[4] Zhao Ji. Grand View of Tea.Zhonghua Book Company,pp.7-46,2013. 